\title{
Alligators - The Illustrated Guide to Their Biology, Behaviour, and Conservation
}

\author{
Kent A. Vliet with photographs by Wayne Lynch \\ John Hopkins University Press, ISBN 9781421433370 (hard cover), pp 293.
}

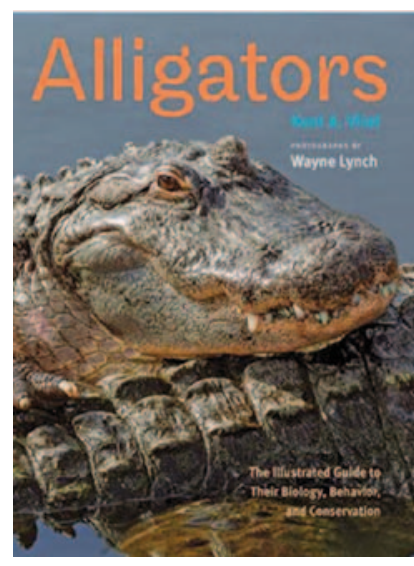

B iologist, educator, and Dcrocodilian researcher,
Dr. Kent Vliet, combines his Dr. Kent Vliet, combines his
expertise in American alligator biology and behaviour with his communication skills to create a comprehensive work on the American alligator that unravels many of the mysteries of alligator natural history. He teams up with talented photographer, Wayne Lynch, who connects many of the biological traits presented in the book with outstanding photographs. 'Alligators' covers all aspects of alligator biology, including conflicts with humans, and targets the general public and enthusiast rather than professional scientist.

The book provides one of the best accounts of the European discovery, classification, and scientific naming of the American alligator with the most complete description of its historical range that I have read, particularly at the range extremes in Virginia and the Rio Grande. Ten common myths and misconceptions about alligators are listed and thereafter debunked or clarified. In Chapter 2, there are outstanding accounts of both paleohistory and the more recent association between alligators and indigenous Americans, after which there is an interesting review of the relationship between early European settlers and alligators. Chapter 3 delivers a broad and detailed study of alligator anatomy and an excellent examination of the alligator's sensory system, including an explanation of how these senses have helped alligators to thrive for millions of years. Chapter 4 offers an overview of alligator habitats, salt tolerance, shaping of microhabitats, movements, and navigation. Chapter 5 gives an in-depth treatment of thermoregulation including response to cold weather and a short assessment of possible climate change impacts on distribution and population viability. Chapter 6 details feeding and predatory behaviour while Chapter 7 presents the evolution and systematics of the Crocodilia supported by an exceptionally clear account of the most recent findings of DNA analysis, accessible to a general audience. Vliet's ground-breaking research and observations on alligator courtship, mating, and copulation are presented in Chapter 8 while Chapter 9 presents detailed descriptions of nest construction, egg laying, embryo development, and hatching. Chapter 10 covers the early life of alligators and the high mortality suffered at this stage, alligator longevity in captivity, and an account of the debate about the maximum size of alligators. Chapter 11 describes the general social behaviour of alligators from birth to adulthood, including social hierarchies, breeding behaviour, vocalisations, and other fascinating aspects. Chapter 12 assesses the problems encountered as alligator country becomes more populated with humans and in Chapter 13 the history of alligator exploitation and conservation is discussed. Finally, there is a nice appendix, 'Where to See Wild Alligators', for those readers wanting to follow up with an in-person experience of these creatures.

Those familiar with Vliet's scientific research on alligator behaviour by might be disappointed that this book has no bibliographical references. Consequently, some readers will be unsure whether statements are based on scientific studies by others or on Vliet's interpretation of previous works. Nevertheless, Vliet does an admirable job of presenting various sides of arguments for most of those issues that are still being debated by the scientific community.

There are several concepts presented in the book that are either scientifically equivocal or have been dispelled. Among those is a central theme that the American alligator was "... close to extinction in the 20th Century" (dustcover), "... reduced to rarity by the 1950s and 1960s" (p. 7), "... concern about the alligator's pending extinction." (p. 40), and "... we might have seen the American alligator go extinct" (p. 248). Since the 1970s, as our understanding of alligator population dynamics has advanced the view that alligators were on the brink of extinction has been widely refuted. Population estimates of $250,000-400,000$ alligators remaining in the late 1960s, presented in Chapter 13 entitled 'From Slaughter to Salvation', do not match up with the notion of near extinction. Neither does a population estimate presented in the section entitled "The Comeback" of 734,000 alligators remaining shortly after they received federal protection in 1970. But the misconception that alligators were close to extinction is planted early in the book and will likely stay with the reader, despite subsequent information that weakens this notion. In addition, Vliet's estimates of pre-Ponce de Leon alligator populations, late 1960 s populations, and current population are also debatable.

Several other less important concepts and debates about crocodilians are presented that appear to be factually incorrect. But these should not overshadow the overall reliability of the book. All in all, 'Alligators' is a wonderful introduction to all aspects of alligator natural history for the general public and an enjoyable read for professional scientists interested in alligators and their relatives.

Allan R. Woodward

Co-chair, North American Region,IUCN - Crocodile Specialist Group E-mail - allan.woodward@cox.net

Received: 19th November 2020 